\title{
Introduction to the Field of Nanotechnology Ethics and Policy
}

\author{
Jonathan D. Linton $\cdot$ Steven T. Walsh
}

Published online: 18 August 2012

(C) Springer Science+Business Media B.V. 2012

\begin{abstract}
Nanotechnologies and nanoscience have generated an unprecedented global research and development race involving dozens of countries. The understanding of associated environmental, ethical, and societal implications lags far behind the science and technology. Consequently, it is critical to consider both what is known and what is unknown to offer a kernel that future work can be added to. The challenges presented by nanotechnologies are discussed. Some initial solutions such as self-regulation and borrowing techniques and tools from other fields are accompanied by a call for further research.
\end{abstract}

Keywords Nanotechnology · Ethics · Policy ·

Social aspects

Nanotechnology has seen an explosive growth in increase in both scientific research and development. This emerging technology has been the focus of increasing consideration in the field of management (see Fig. 1). However, the ethical and policy considerations to date are clearly trailing (Groves et al. 2011). Consequently, this special issue was developed to take stock of where the field is, to move it forward, and act as a call and rallying point for further research. In order to offer the best possible view on this very young and dynamic field, two introductions are offered to this cluster of papers. An academic introduction, that you are currently reading,

\footnotetext{
J. D. Linton ( $\square)$

University of Ottawa, Ottawa, Canada

e-mail: drjdlinton@gmail.com

S. T. Walsh

Anderson Schools of Management, University

of New Mexico, Albuquerque, NM, USA

e-mail: swalsh91@comcast.net
}

and an introduction by a policy maker with a dual educational role (Stinnett 2012) to offer a different perspective on this issue of great future consequence.

Nanotechnology is unlike any science/technology field to date, due to the widespread interest it has created with not only the traditional funders of science and technological activity, but many countries that traditionally do not fund advanced research. The unprecedented global competition in this area creates concerns of ethics being sacrificed in search of competitive advantage at not only the corporate level, but the national level as well. While this is clearly a possibility, research in this issue suggests the likelihood of more positive outcomes. Prior to introducing this research and what needs to be done in the future it is worth quickly making some introductory comments about opportunities and threats that nanotechnologies offer's society. Our task here is to move away from fictitious nightmare scenarios offered in books like Prey (Chricton 2002), while outlining the uncertainties associated with nanotechnologies and what these uncertainties may imply for society.

There is a belief that nanoscience and nanotechnologies will transform most of the products we use and allow for the development of many entirely new products (Barras 1986; Linton and Walsh 2008). Such a transformation may be much greater than the impact the transistor has had on communications, electronics, and information technology during the twentieth century. Through control at the atomic level it is not only possible to make very small machines, but the products that we currently use can be made with greatly enhanced abilities. Traditional engineering materials could be developed to be free of flaws allowing for much greater strength, while utilizing less material. Specific properties could also be introduced to these materials by introducing flaws, other materials or alternative structures in exactly the desired location and configuration. 


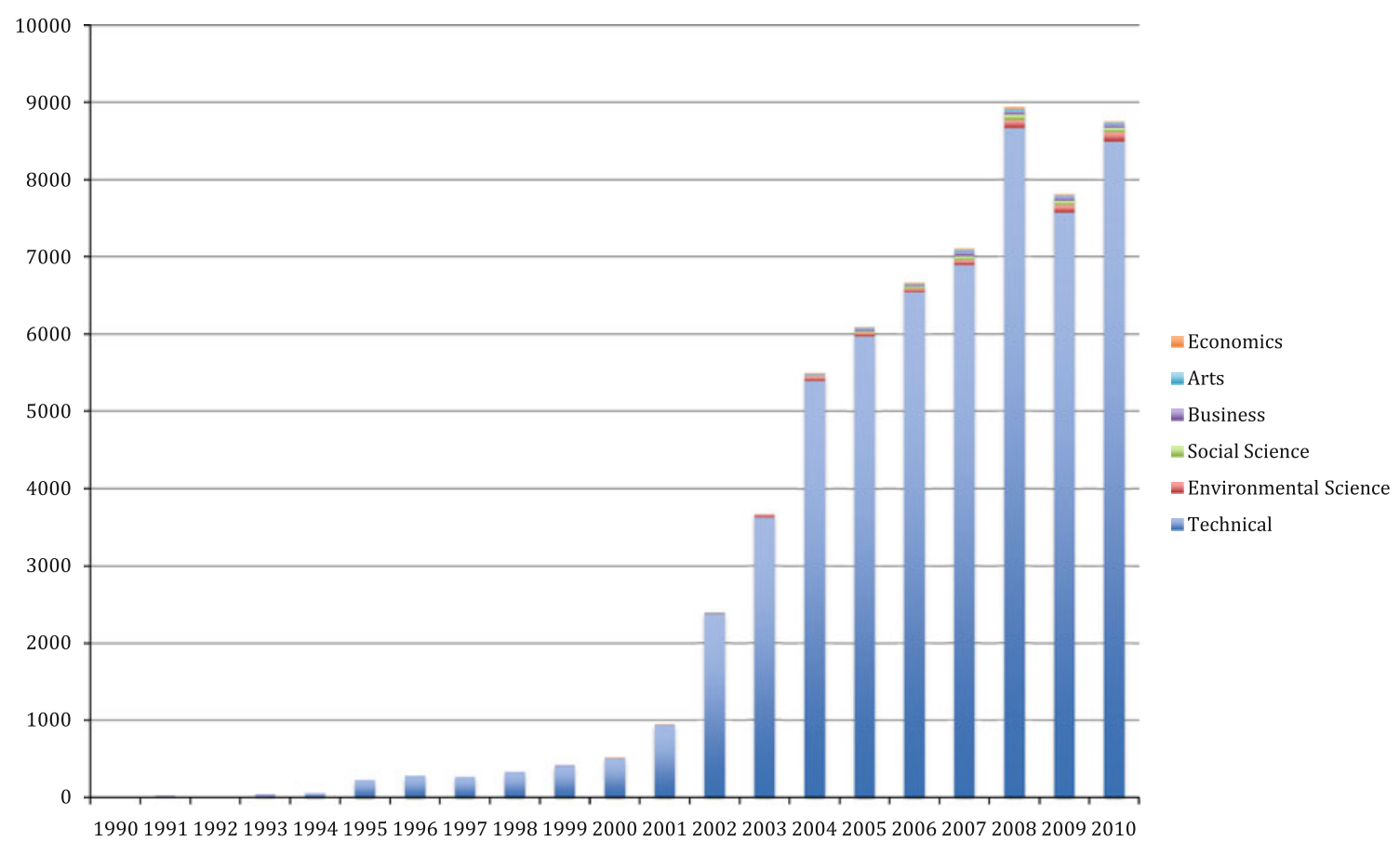

Fig. 1 Summary of the number of papers on the subject of nanotechnology as a function of year and type-1990 to 2010, inclusive (Source Scopus, December 2011)

Instead of utilizing a great deal of energy and material for production, we could enter an era that would see the building of desired products one atom at a time. Such an era would destroy the value of many old skills and replace it with not only tremendous opportunity for a more sustainable society, but create tremendous dislocation of people and transfer of economic value away from the traditional capabilities and competencies to the owners of nanotechnology enhanced capabilities and competencies.

Faced with such a possibility, countries are pursuing nanosciences and nanotechnologies in hope of harvesting the potential, but still elusive benefits, and avoiding the transfer of economic opportunity away from their traditional industries and strengths to other jurisdictions. Hence pursuit of nanotechnology is both an investment and an insurance policy against future loss of economic, industrial, military, and technological relevance. Having given brief consideration to the drivers behind nanoscience and nanotechnology, the threat uncertainty regarding unintended consequences of the technology is considered.

The relative lack of insight into issues associated to environment, health, and social impact of nanotechnologies is a great concern, due to the potential of nanotechnologies to be a transformative technology. For example, reasonable concerns exist that exposure to materials at the nanoparticle level will effect human health differently. Such changes can have either a positive or negative effect. For example, ancient Indian ayurvedic medicinal practices suggest that human exposure to mercury at the nanotechnology level has greatly reduced toxicity (Mishra 2003). On the other hand, exposure to smaller particles of asbestos is toxic (Wildavsky 1995). Faced with uncertainty and the specter of serious potential danger, the likelihood of panics as a consequence of limited understanding as has been the case with many past public health and environment issues is highly likely (Wildavsky 1995). Figure 1, illustrates how the environmental and social impacts are clearly trailing scientific investigation and there is a need to ensure that the gap does not continue in an uncontrolled way-until a panic response is elicited by a real or perceived disaster. This special issue contributes to this need in a number of different ways.

Goueva et al. (2012) consider whether the pursuit of nanotechnologies result in a trade off between ethics and economics-i.e., a race-to-the-bottom. They find that scientific research and ethical environment of the country or jurisdiction seem unrelated for pure and applied research. However, as one approaches commercialization an ethical environment is related to higher levels of patent and product introductions-i.e., a race-to-the-top. Having considered the ethical environment from a rather broad perspective, the special issue moves to consideration of the ethics of individual researchers.

Fink et al. (2012) suggest that the tremendous uncertainty associated with nanotechnologies calls for researchers to consider the impact of their work while it is being conducted. By ensuring researchers consider, reflect on and study the possible impacts of their own work a code of 
conduct could be developed that at the very least identify risk and at best partially or completely mitigate it. Historically, researchers have often separated themselves from the impacts of their work. There are notable exceptions to this sort of separation, such as the Russell-Einstein Manifesto and the work of Pugwash in relation to nuclear weapons (Ionno Butcher 2005). Self-examination of one's work will allow for earlier identification of at least some of the risks and also possibly the opportunities associated with research advances in nanotechnology. Failure to approach nanotechnologies in this manner could easily result in a backlash against nanotechnology, such as has been seen with other technologies like genetically modified organisms (GMO) (Griesse 2007). The researchers are well advised to selfregulate to better reduce the need and likelihood of regulations being applied to them by those who have a lesser understanding of the science. As the evidence to date is that nanotechnology advances fail to meet the precautionary principle, this is a critical point to note.

While such an approach of self-monitoring and reflection is helpful, it is important that societal implications both positive and negative receive greater attention. Ensuring that a component of nanoscience and nanotechnology research be aimed at the environmental and social sciences is clearly needed as it can assist in identifying the negative-impact of uncertainties that we need to protect against and the positive-impact of uncertainties that we can benefit from by better harnessing.

$\mathrm{Lu}$ et al. (2012) identify the emerging, but existing nature, of the literature intended to mitigate risk and maximize opportunities provided by nanotechnologies. They find that while appropriate studies are emerging in response to advances in nanotechnology that this work is still in its early stages.

More consideration needs to be given to the knowledge and tools that we already have from other fields that are applicable. For example, tools like Failure Mode Effect Analysis can be used to identify potential problems and appropriate mitigation approaches for new products and processes (Pillay and Wang 2003; Linton 2003). Roadmapping (Kostoff and Schaller 2001; Walsh 2004) can be used to identify barriers in both technological and social innovation (Linton 2009) that need to be addressed. While this cluster of papers seeks to inform, its primary purpose is to call attention to the tremendous gaps and needs in this area. The fundamental and uncertain nature of nanotechnologies calls for continued study of the societal and ethical implications of nanotechnology research and application. The globally dispersed nature of these studies enhances both the complexity and need of this consideration.

\section{References}

Barras, R. (1986). Towards a theory of innovation in services. Research Policy, 15(4), 161-173.

Chricton, M. (2002). Prey. New York: Harper Collins.

Fink, M., Harms, R., \& Hatak, I. (2012). Nanotechnology and ethics: The role of regulation versus self-commitment in shaping researchers' behaviour. Journal of Business Ethics. doi:10.1007/ s10551-012-1431-2.

Goueva, R., Linton, J. D., Montoya, M., \& Walsh, S. T. (2012). Emerging technologies and ethics: A race to the bottom or the top? Journal of Business Ethics. doi:10.1007/s10551-012-1430-3.

Griesse, M. A. (2007). Developing social responsibility: Biotechnology and the case of DuPont in Brazil. Journal of Business Ethics, 73(1), 103-118.

Groves, C., Frater, L., Lee, R., \& Stokes, E. (2011). Is there room at the bottom for CSR? Corporate social responsibility and nanotechnology in the UK. Journal of Business Ethics, 101(4), $525-552$

Ionno Butcher, S. (2005). The origins of the Russell-Einstein Manifesto. Fredricksburg, VA: Cardinal Press.

Kostoff, R. N., \& Schaller, R. R. (2001). Science and technology roadmaps. IEEE Transactions on Engineering Management, 48(2), 132-143.

Linton, J. D. (2003). Facing the challenges of service automation: An enabler for e-commerce and productivity gain in traditional services. IEEE Transactions on Engineering Management, 50(4), 478-484.

Linton, J. D. (2009). De-babelizing the language of innovation. Technovation, 29(11), 729-737.

Linton, J. D., \& Walsh, S. T. (2008). A theory of innovation for process-based innovations such as nanotechnology. Technological Forecasting and Social Change, 75(5), 583-594.

Lu, L. Y. Y., Lin, B. J. Y., Liu, J. S., \& Yu, C. -Y. (2012). Ethics in nanotechnology: What's been done? What's missing? Journal of Business Ethics (in press).

Mishra, L. C. (Ed.). (2003). Scientific basis for ayurvedic therapies. Boca Raton, FL: CRC Press.

Pillay, A., \& Wang, J. (2003). Modified failure mode and effects analysis using approximate reasoning. Reliability Engineering and System Safety, 79(1), 69-85.

Stinnett, R. (2012). Practitioners introduction: Nanotechnology policy and education. Journal of Business Ethics. doi:10.1007/s10551012-1429-9.

Walsh, S. T. (2004). Roadmapping a disruptive technology: A case study the emerging microsystems and top-down nanosystems industry. Technological Forecasting and Social Change, 71(1-2), 161-185.

Wildavsky, A. (1995). But is it true? A citizen's guide to environmental health and safety issues. Cambridge, MA: Harvard University Press. 